\title{
Autonomic reactions during posterior cranial fossa surgery
}

\author{
Rumyantseva M.V., Petrova A.O., Nazarov R.V., Kondratiev A.N. \\ Russian Neurosurgical institute of Professor A. L. Polenov, \\ branch of the "Medical and investigation center of V.A.Almazov" Ministry Of Health Of \\ Russia
}

\begin{abstract}
During operations on posterior fossa tumors specific autonomic reactions could occur. The potential danger of these reactions and speed of their development make it necessary to detect them.

Since 1989 in our Department we successfully apply the method of anesthesia, which includes combined use of fentanyl and clonidine. This method of anesthesia creates conditions for neurovegetative stability which are optimal for the brain surgery (the preservation of autoregulation of cerebral circulation, cerebral perfusion, the possibility of neurophysiological monitoring, etc.) and allows to detect autonomic reactions.

The 1-st type of vegetative reactions is the consequence of irritation of some local centers or nuclei of cranial nerves relevant to the regulation of blood pressure and heart rate.

The 2-nd type of vegetative occur when there is a massive loss of brain function resulting from relative or absolute hypoperfusion, which lead to irritation of the midline structures with subsequent hypercatecholaminemia.

Emergence of a more selective alfa2-adrenoagonist (Dexmedetomidin), allows to consider it as choice option for application in the structure of anesthesia.
\end{abstract}

Aim: to evaluate the efficacy of dexmedetomidine as a component of anesthesia during operations, accompanied by the appearance vegetative reactions.

\footnotetext{
Materials and methods:

The study included 80 patients underwent the elective operations on posterior fossa tumors in RNHI of prof. A. L. Polenov.

Induction of anesthesia included: muscle relaxants (pipecuronium 0.1 $\mathrm{mg} / \mathrm{kg}$ followed by rocuronium $0,6 \mathrm{mg} / \mathrm{kg}$ ), hypnotic (propofol 1,5-2,35 $\mathrm{mg} / \mathrm{kg}$ ), an opioid analgesic (fentanyl 3,54-5,9 $\mu \mathrm{g} / \mathrm{kg}$ ) + ALPHA2adrenoagonists (clonidine or dexmedetomidine). All patients were divided into three groups depending on ALPHA2-adrenoagonists and dosages: group I (22 patients) were administered clonidine $1-2,63 \mu \mathrm{g} /$ $\mathrm{kg}$, in group II (38 patients) - dexmedetomidine of 1,05 to $2,33 \mu \mathrm{g} / \mathrm{kg}$ in group III (20 patients) - dexmedetomidine $0,54-0,95 \mathrm{mg} / \mathrm{kg}$.

Maintenance of anesthesia: hypnotic (propofol $2-8,4 \mathrm{mg} / \mathrm{kg} / \mathrm{h}$ ), opioid analgetic (fentanyl $0,65-2,08 \mu \mathrm{g} / \mathrm{kg} / \mathrm{h}$ ) + ALPHA2-adrenoagonists (in group I - clonidine $0,22-0,81 \mu \mathrm{g} / \mathrm{kg}$, in group II - dexmedetomidine $0,21-1,04 \mu \mathrm{g} / \mathrm{kg} / \mathrm{h}$ in group III- dexmedetomidine $0,11-0,42 \mu \mathrm{g} / \mathrm{kg} /$ h).

Monitoring of hemodynamic -"NihonKohden" and "PICCO PULSION".

All operations were carried out under the control of the depth of sedation -"BISAspect".
}

\section{Results}

In all three groups, the 1-st type of vegetative reaction were observed in the form of short episodes of bradiarytmias and/or arterial hypertension, and autonomic reactions of the 2-nd type (I -II groups) in the form of persistent hypertension.

In group I, the 1-st type of reactions were observed in 14 patients (64\%), the 2 -nd type - in 1 case $(0,05 \%)$.

In the second group the 1 -st type of reactions were observed in 24 patients $(63 \%)$, the 2 -nd type - 1 case $(0,03$ percent).

In group III, the 1 -st type of reactions were observed in 14 patients $(70 \%)$.

\begin{tabular}{|c|c|c|c|}
\hline & Group I & Group II & Group III \\
\hline $\begin{array}{c}\text { 1-st type of } \\
\text { reactions }\end{array}$ & $64 \%$ & $63 \%$ & $70 \%$ \\
\hline $\begin{array}{c}\text { 2-nd type of } \\
\text { reactions }\end{array}$ & $0,05 \%$ & $0,03 \%$ & $0 \%$ \\
\hline
\end{tabular}

\section{Conclusion}

Application of dexmedetomidine in the structure of anesthesia allows to identify emerging autonomic response and could be applied during operations on posterior fossa tumors. 